\title{
Sosialisasi Penerapan Pedoman Umum Ejaan Bahasa Indonesia dalam Forum Ustaz dan Ustazah Kecamatan Banjarmasin Timur
}

\author{
Jamiatuh Hamidah ${ }^{1}$, Akhmad Syakir ${ }^{2}$ \\ ${ }^{1,2}$ Universitas Muhammadiyah Banjarmasin \\ email : midah.beswan@gmail.com ${ }^{1}$, ahmadsyakir02@gmail.com ${ }^{2}$
}

\begin{abstract}
The purpose of this socialization activity is to provide training to ustaz / ustazah about Indonesian language rules and standard grammar and to improve the linguistic competence of the ustaz / ustazah. The benefits that are expected from this activity are increasing the knowledge or insight of the ustaz / ustazah towards Indonesian language rules, increasing understanding of absorption elements, and avoiding mistakes in writing Indonesian vocabulary. The method of this socialization activity is by lecturing, conveying general Indonesian rules and guidelines. The activity is carried out in one day, with the target of TPA teachers who are members of the Ustaz and Ustazah Forums, East Banjarmasin District. The activity was carried out at TPA Unit 201 Darul Mu'minin, which is located at Jalan Pramuka Komplek Kenanga (Cinta Puri) RT.07, East Banjarmasin, South Kalimantan. The number of participants who attended was 211 people from 39 TPA Units scattered in East Banjarmasin District. The result of the socialization of the General Guidelines for Indonesian Spelling to the East Banjarmasin Ustaz-ustazah Forum was an increase in the competence and knowledge of ustaz-ustazahs regarding the Indonesian language guidelines and rules.
\end{abstract}

Keywords: socialization, rules, ustaz, ustazah.

\begin{abstract}
Abstrak
Tujuan dilaksanakan kegiatan sosialisasi ini adalah untuk memberikan pelatihan kepada para ustaz/ustazah tentang kaidah Bahasa Indonesia dan tata bahasa baku dan untuk meningkatkan kompetensi kebahasaan para ustaz/ustazah. Manfaat yang diharapkan dari kegiatan ini adalah meningkatkan pengetahuan atau wawasan para ustaz/ustazah terhadap kaidah bahasa Indonesia, meningkatkan pemahaman terhadap unsur serapan, serta menghindari kesalahan penulisan kosa kata bahasa Indonesia. Metode kegiatan sosialisasi ini adalah dengan ceramah, menyampaikan kaidah dan pedoman umum Bahasa Indonesia. Kegiatan dilaksanakan dalam satu hari, dengan sasaran para pengajar TPA yang tergabung dalam Forum Ustaz dan Ustazah Kecamatan Banjarmasin Timur. Kegiatan dilaksanakan di TPA Unit 201 Darul Mu'minin, yang beralamat di Jalan Pramuka Komplek Kenanga (Cinta Puri) RT.07 Banjarmasin Timur, Kalimantan Selatan. Jumlah peserta yang hadir sebanyak 211 orang dari 39 Unit TPA yang tersebar di Kecamatan Banjarmasin Timur. Hasil kegiatan sosialisasi Pedoman Umum Ejaan Bahasa Indonesia kepada Forum Ustaz-ustazah SeBanjarmasin Timur adalah meningkatnya kompetensi dan pengetahuan ustaz-ustazah terhadap pedoman dan kaidah Bahasa Indonesia.
\end{abstract}

Kata Kunci: sosialisasi, kaidah, ustaz, ustazah.

Artikel diterima : 20 Mei 2021

direvisi : 27 Mei 2021

disetujui : 1 Juni 2021 


\section{Pendahuluan}

Taman Pendidikan Al Quran (TPA) merupakan lembaga pendidikan nonformal yang bertujuan untuk mendidik anak-anak agar mampu membaca $\mathrm{Al}$ Quran dengan baik, menulis huruf hijaiyah, serta memahami dan mengamalkan Al Quran dalam kehidupan seharihari. Ustaz dan ustazah sebagai pengajar memegang peranan penting terhadap pencapaian pembelajaran di TPA. Ustaz dan ustazah adalah perkembangan dari istilah ustaz yang berarti pendidik atau guru. Dalam KBBI V, ustaz/ustazah diartikan sebagai guru agama atau sebagai sebutan/sapaan. Ustaz/ustazah lazim digunakan sebagai sapaan kepada guru TPA, guru mengaji, atau guru di sekolah berbasis Islam.

Dalam kegiatan pembelajaran maupun administrasi, ustaz/ustazah tidak terlepas dari penggunaan Bahasa Arab. Hal ini memengaruhi tata cara dalam penulisan yang menggunakan Bahasa Indonesia. Sering terjadi, kesulitan dalam menuliskan terjemahan atau penyerapan bahasa Indonesia yang berasal dari Bahasa Arab. Misalnya dalam menuliskan sholat, biasa ditulis shalat atau sholat. Padahal dalam kaidah bahasa baku, penulisan yang benar adalah salat. Selain itu misalnya dalam penulisan ustaz/ah, menggunakan ustadz atau ustad, hal ini karena pengaruh penerjemahan bahasa Arab itu sendiri

Dalam urusan administrasi, ustazustazah juga sering mengalami kekeliruan ketika menulis kosa kata tertentu. Misalnya untuk surat-menyurat atau pelaporan kepada pihak terkait, masih terdapat penggunaan Bahasa Indonesia yang tidak sesuai dengan kaidahnya.

Terjadinya masalah tersebut bukan karena pendidikan guru TPA yang masih rendah. Rata-rata ustaz-ustazah sudah bergelar Sarjana Pendidikan Islam (S.Pd.I), ada yang bergelar Sarjana Agama (S.Ag.), dan sisanya merupakan Sarjana umum baik S-1 maupun D-3 (bergelar S.Pd., SH. dan atau A.Md.), serta lulusan sekolah Madarasah Aliyah dan Pondok
Pesantren. Sebagian besar mengaku belum pernah mengikuti kegiatan sosialisasi pedoman umum ejaan Bahasa Indonesia.

Berdasarkan latar belakang tersebut, maka dosen Pendidikan Bahasa Indonesia bekerja sama dengan Lembaga Pembinaan dan dan Pengembangan TK Al Quran serta Badan Komunikasi Pemuda Remaja Masjid Indonesia, mengadakan sosialisasi pedoman umum ejaan bahasa Indonesia. Salah satu materi yang disampaikan berkaitan dengan tata bahasa baku dan kaidah penulisan unsur serapan serta tanda baca.

Tujuan dilaksanakan kegiatan sosialisasi ini adalah untuk memberikan pelatihan kepada para ustaz/ustazah tentang kaidah Bahasa Indonesia dan tata bahasa baku dan untuk meningkatkan kompetensi kebahasaan para ustaz/ustazah. Manfaat yang diharapkan dari kegiatan ini adalah meningkatkan pengetahuan atau wawasan para ustaz/ustazah terhadap kaidah bahasa Indonesia, meningkatkan pemahaman terhadap unsur serapan, serta menghindari kesalahan penulisan kosa kata bahasa Indonesia

Kegiatan serupa pernah dilakukan oleh (Muzaki et al., 2019). dengan tema Pengenalan Pedoman Umum Ejaan Bahasa Indonesia (PUEBI) dalam Mengembangkan Kemampuan Berbahasa Indonesia yang Baik dan benar bagi Para Guru. Hasil dari kegiatan tersebut adalah meningkatnya wawasan guru dalam proses pembelajaran di kelas dan guru dapat membuat soal-soal ujian menggunakan Bahasa Indonesia yang baik dan benar.

\section{Metode Pelaksanaan}

Metode kegiatan sosialisasi ini adalah dengan ceramah, menyampaikan kaidah dan pedoman umum Bahasa Indonesia. Kegiatan dilaksanakan dalam satu hari, dengan sasaran para pengajar TPA yang tergabung dalam Forum Ustaz dan Ustazah Kecamatan Banjarmasin Timur. Kegiatan dilaksanakan di TPA Unit 201 Darul Mu'minin, yang beralamat di 
Jalan Pramuka Komplek Kenanga (Cinta Puri) RT.07 Banjarmasin Timur, Kalimantan Selatan. Jumlah peserta yang hadir sebanyak 211 orang dari 39 Unit TPA yang tersebar di Kecamatan Banjarmasin Timur.

\section{Tahap Persiapan dan Perencanaan}

Kegiatan pengabdian kepada masyarakat oleh Perguruan Tinggi harus dipersiapkan secara matang, terprogram, terintegrasi, dan ada keberlanjutan (Santosa, 2018). Oleh karena itu, tim melakukan persiapan dan perencanaan dengan melakukan survei untuk memperoleh data yang diperlukan.

Data yang diperoleh diantaranya dari dokumen surat-menyurat atau dokumen administrasi yang dilakukan oleh ustaz/ ustazah. Persiapan tempat juga dilakukan dengan berkoordinasi kepada pengelola TPA Unit 201 Darul Mu'minin, yang beralamat di Jalan Pramuka Komplek Kenanga (Cinta Puri) RT.07 Banjarmasin Timur. Tempat ini dipilih karena memiliki ruangan yang cukup luas dan mudah dijangkau oleh semua peserta.

\section{Tahap Pelaksanaan}

Kegiatan dilaksanakan pada hari Selasa, tanggal 17 November 2020. Pelaksanaan sosialisasi diikuti oleh 211 orang ustaz dan ustazah yang berasal dari seluruh TPA Di Kecamatan Banjarmasin Timur.

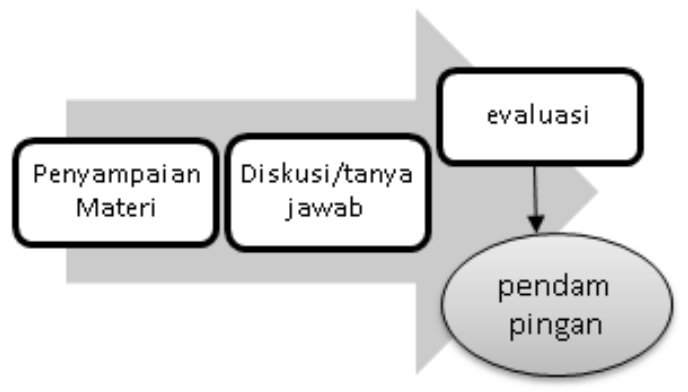

Gambar 1. Desain pelaksanaan kegiatan

\section{Tahap Evaluasi dan Rencana Tindak Lanjut}

Setelah penyampaian materi selesai, peserta diberikan kesempatan untuk memberikan tanggapan atau menyampaikan pertanyaan. Evaluasi dilakukan untuk mengukur tingkat pemahaman peserta terhadap materi yang diberikan. Evaluasi berupa pertanyaan lisan kepada beberapa peserta dan langsung. Setelah diperoleh hasil evaluasi, maka dilakukan rencana tindak lanjut berupa pembimbingan kepada para ustaz/ustazah melalui grup aplikasi Whatsapp.

\section{Hasil dan Pembahasan}

Setelah kegiatan dilaksanakan, hasilnya adalah ustaz/ustazah sudah memahami kaidah penulisan yang berkaitan dengan penyerapan dan bahasa baku. Sebagian besar ustaz/ustazah juga telah memasang aplikasi KBBI V dan aplikasi PUEBI yang bisa diunduh dari playstore. Kedua aplikasi ini nantinya akan sangat membantu apabila mereka kesulitan dalam menuliskan kosakata yang benar sesuai kaidah.

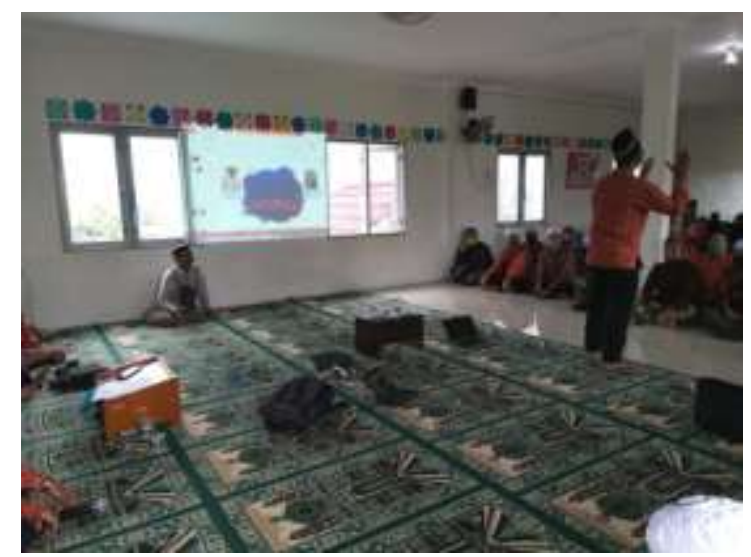

Gambar 2. Pemaparan materi tentang Pedoman Umum Ejaan Bahasa Indonesia

Dalam penyampaian materi tentang Pedoman Ejaan Bahasa Indonesia, pemateri menyelingi dengan mengemukakan contoh kosa kata yang sering keliru dalam penulisannya. Banyak yang mengira bahwa penulisan sudah benar, karena sering digunakan. Padahal penulisan kosa kata tersebut keliru. Setelah pemateri menjelas- 
kan kaidah yang benar, barulah mereka memahaminya.

Pada saat kegiatan berlangsung, para ustaz/ustazah juga dibimbing mengunduh aplikasi KBBI dan PUEBI. Setelah itu mereka diajarkan cara penggunaan kedua aplikasi tersebut. Banyak pertanyaan yang mereka ajukan terkait aplikasi tersebut. Setelah mereka bisa menggunakannya, tidak sedikit yang menyatakan bahwa mereka sangat terbantu dan merasa mudah untuk mencari tahu tentang kata baku. Bahkan ada yang menyadari kalau selama ini telah menggunakan kosa kata yang tidak baku untuk keperluan resmi, seperti sering menulis masjid dengan mesjid.

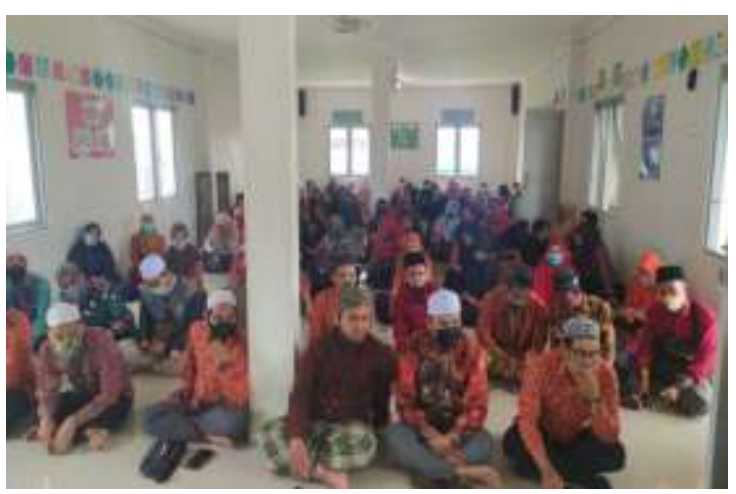

Gambar 3. Peserta pelatihan

\section{Aplikasi KBBI dan PUEBI}

Kementerian Pendidikan dan Kebudayaan, melalui Badan Pengembangan dan Pembinaan Bahasa, menyediakan aplikasi KBBI dan PUEBI yang dapat diunduh di play store bagi pengguna smartphone. Apabila melakukan pencarian aplikasi di play store, cukup dengan mengetik kata kunci KBBI dan PUEBI, maka akan muncul gambar seperti berikut:
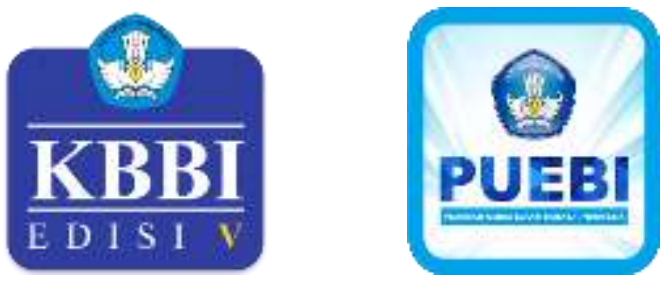

Gambar 4. Tampilan aplikasi playstore

Setelah menemukan logo seperti di atas, pengguna dapat mengklik install.
Cara menggunakan aplikasi KBBI sangat mudah. Ada 4 kategori pilihan pencarian, yaitu kelas kata, ragam, bahasa, dan bidang. Apabila pengguna ingin mencari kosa kata misalnya pada kelas kata, maka tinggal klik kolom kelas kata. Nanti akan muncul berbagai jenis kelas kata seperti nomina, verba, adjektiva, dan lain-lain. Selanjutnya pada kelas kata yang dipilih (misalnya nomina), klik pada tulisan nomina, maka pada aplikasi akan muncul daftar kata yang termasuk nomina. Untuk mengetahui arti kata tersebut, tinggal lanjutkan klik pada kata yang dipilih.

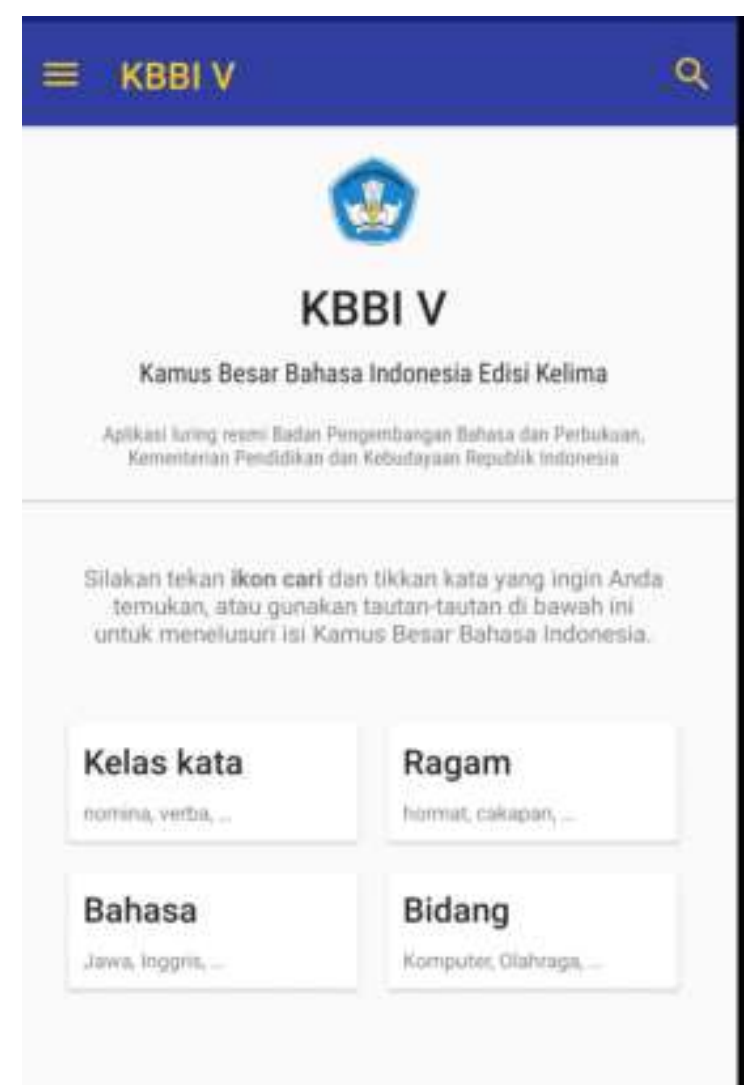

Gambar 5. Tampilan menu KBBI V di aplikasi smartphone

Apabila pengguna ingin mengetahui arti kosa kata tertentu dengan cepat, dapat juga langsung menekan tombol pencarian $(\varphi)$. Kemudian ketik kosa kata yang dikehendaki, maka akan muncul arti atau makna nya berdasarkan KBBI. Jika kata yang diketik tidak baku, aplikasi akan dengan sendirinya menunjukkan kata baku yang benar. 
Di samping itu, penggunaan aplikasi PUEBI juga sangat mudah. Jika aplikasi sudah terpasang, pengguna bisa langsung masuk ke menu utama, dengan 4 pilihan menu pemakaian huruf, penulisan kata, pemakaian tanda baca, dan penulisan unsur serapan.

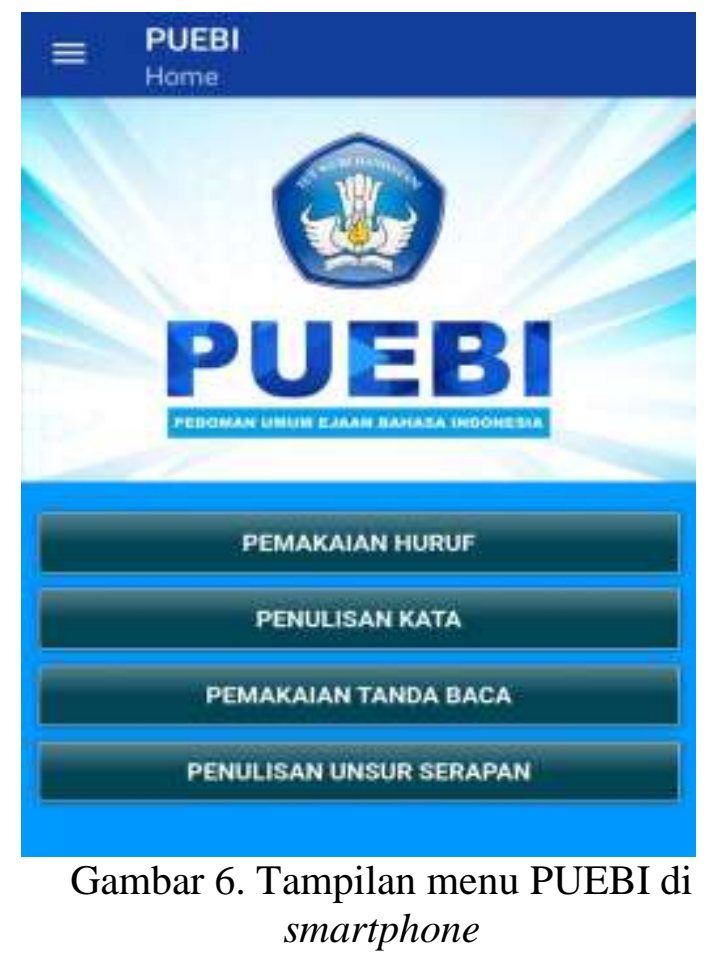

Pada menu pemakaian huruf, jika diklik akan muncul pilihan sub-menu seperti: huruf abjad, huruf vokal, huruf konsonan, huruf diftong, gabungan huruf, huruf capital, huruf miring, dan huruf tebal. Selanjutnya bisa pilih kolom submenu sesuai yang diinginkan, maka nanti akan muncul uraian kaidah Bahasa Indonesia, lengkap disertai dengan contohcontoh.

Ketika sudah selesai digunakan, pengguna bisa langsung keluar dari aplikasi dengan menutup aplikasi tersebut. Kelebihan dari kedua aplikasi ini adalah tentu saja karena bentuknya yang praktis dan mudah dibawa kemana-mana, jika dibandingkan dengan buku KBBI yang versi cetaknya sangat tebal dan berat. Kelebihan lainnya adalah pengguna tidak memerlukan biaya data atau kuota karena aplikasi ini bisa digunakan tanpa koneksi jaringan internet.

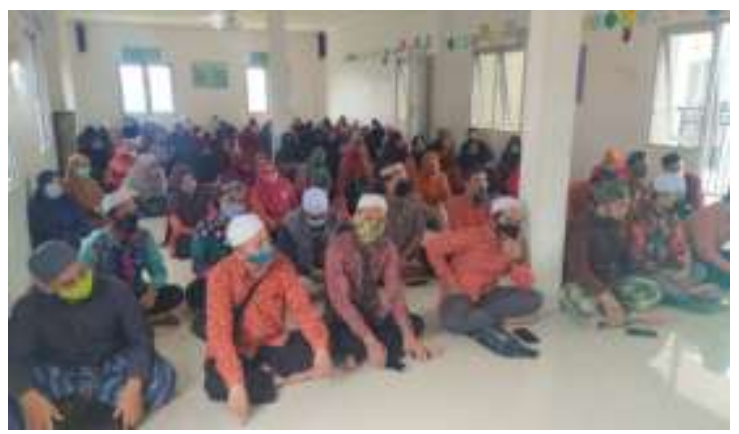

Gambar 7. Sesi tanya jawab

Sebelum menutup kegiatan, pemateri melakukan evaluasi terhadap materi yang disampaikan, untuk mengukur tingkat pemahaman peserta. Evaluasi berupa pertanyaan lisan kepada beberapa peserta dan langsung dijawab. Setelah diperoleh hasil evaluasi, maka dilakukan tindak lanjut yang dilakukan adalah berupa pembimbingan kepada para ustaz/ustazah melalui grup whatsapp. Hal ini karena banyak permintaan dari para peserta untuk dibuatkan grup whatsapp, agar sewaktuwaktu bisa berkonsultasi atau menanyakan masalah kebahasaan yang belum mereka pahami.

\section{Simpulan}

\section{Penutup}

Berdasarkan uraian di atas, dapat disimpulkan bahwa kegiatan sosialisasi Pedoman Umum Ejaan Bahasa Indonesia dalam Forum Ustaz-ustazah Kecamatan Banjarmasin Timur telah berhasil. Wawasan dan Pengetahuan kebahasaan serta kaidah Bahasa Indonesia yang baik dan benar, yang dimiliki oleh ustaz/ ustazah juga meningkat. Di samping itu, ustaz/ustazah menjadi lebih terampil dalam menggunakan teknologi/smart phone untuk menunjang berbagai kegiatan pembelajaran atau lainnya.

\section{Saran}

Saran untuk pelaksanaan kegiatan selanjutnya bisa diadakan pelatihan penulisan surat-menyurat bagi ustaz- 
ustazah. Pelatihan keterampilan berbicara (public speaking) juga dapat menjadi pilihan untuk meningkatkan kemampuan ustaz/ustazah.

\section{Ucapan Terima Kasih}

Terima kasih kami sampaikan kepada anggota forum ustaz-ustazah Kecamatan Banjarmasin Timur yang telah mengikuti kegiatan ini dengan antusias dari awal hingga akhir. Terima kasih juga kami sampaikan pada BKPRMI (Badan Komunikasi Pemuda Remaja Mesjid Indonesia) Wilayah Kalimantan Selatan atas kerja sama dan dukungannya dalam kegiatan ini.

\section{Daftar Pustaka}

Alwi, H. (2007). Tata Bahasa Baku Bahasa Indonesia. Jakarta: Balai Pustaka.

Amirotunnikmah, D. (2016). Kompetensi Kepribadian Ustadz Ustadzah Di Pondok Pesantren Al Hidyah Karangsuci Purwokerto Kabupaten Banyumas. Skripsi. IAIN Purwokerto.

Kementerian Pendidikan dan Kebudayaan. (2018). Kamus Besar Bahasa Indonesia, Edisi $V$. Badan Pengembangan dan Pembinaan Bahasa.

Muzaki, A., Chadis, C., \& Agustin, Y. (2019). Pengenalan Pedoman Umum Ejaan Bahasa Indonesa (PUEBI) dalam Mengembangkan Kemampuan Berbahasa Indonesia yang Baik dan Benar bagi para Guru. Jurnal PkM Pengabdian Kepada Masyarakat, 2(02), 82-86.

Santosa, D. H. (2018). Pendampingan pengembangan potensi bidang bahasa, seni sastra, dan seni pertunjukan Jawa di Desa Beji Kecamatan Ngawen Kabupaten Gunungkidul menuju desa berbudaya Jawa. Bakti Budaya: Jurnal Pengabdian Kepada Masyarakat, 1(1), 18-29. 